\title{
artículos
}

\section{De sueños y realidades. La gestión del patrimonio cultural en contextos rururbanos}

Pilar Ordóñez Vergara

Instituto Andaluz del Patrimonio Histórico (IAPH)

\section{RESUMEN}

En el texto que sigue 1 , se hacen algunas consideraciones a propósito del patrimonio cultural en contextos rururbanos, con especial atención al paisaje. A partir de la aproximación a dos casos en la provincia de Málaga, se plantean algunas de las limitaciones para la gestión del patrimonio cultural entendida como proceso que va del conocimiento y reconocimiento a la intervención. Las limitaciones vienen impuestas tanto por la legislación urbanística como por la propia legislación sectorial, así como por los convencionalismos que imperan en su práctica.

PALABRAS CLAVE: Gestión del Patrimonio Cultural/ Espacios rururbanos/ Paisaje Cultural/ Málaga.

About dreams and realities. The management of the cultural heritage in rururbans contexts

ABSTRACT

Following text exposes some considerations about cultural heritage in rururban contexts with special focus in the landscape. With a closer look on two cases in the province of Málaga it presents some of the limitations for the management of cultural heritage understood as a process which starts with the knowledge and recognition of the cultural good. These limitations are imposed as well by urban legislation as well as by legislation in its own sector as also by some conventions ruling its practice.

KEY WORDS: Cultural Heritage Management/ Rural-urban sites/ Cultural Landscape/ Málaga.

\author{
«¿En qué consiste la barbarie sino en se \\ incapaz de reconocer la excelencia?» \\ J. P. ECKermann, Conversaciones con Goethe.
}

1. Sobre El PAISAJE COMO OBJETO PATRIMONIAL EN EL MEDIO RURAL Y EL URBANISMO.

Para empezar, parto del concepto de paisaje como producto histórico, expresión de las estrategias de producción y reproducción social de una comunidad en su medio, susceptible de lectura e interpretación. El paisaje en el medio rural que hoy

* ORDÓÑEZ VERGARA, Pilar: "De sueños y realidades. La gestión del patrimonio cultural en contextos rururbanos", en Boletín de Arte, n 30-31, Departamento de Historia del Arte, Universidad de Málaga, 2009-2010 págs. 403-425. Fecha de recepción: Junio de 2009.

1 Este texto responde básicamente a lo expuesto en la sesión del 11 de marzo de 2009 del Master "Desarrollos sociales de la cultura artística" del Departamento de Historia del Arte de la Universidad de Málaga. Amplía algunas de las ideas planteadas en un trabajo anterior inédito (un resumen del cual fue objeto de una comunicación en los Encuentros de primavera de la Universidad de Cádiz en 1997, publicada en sus Actas [2001]) corrigiendo algunos errores, matizando algunas de las conclusiones y corroborando la tesis principal que allí se mantenía. Agradezco a los profesores Pedro Aguayo de Hoyos, Diego Compán Vázquez 


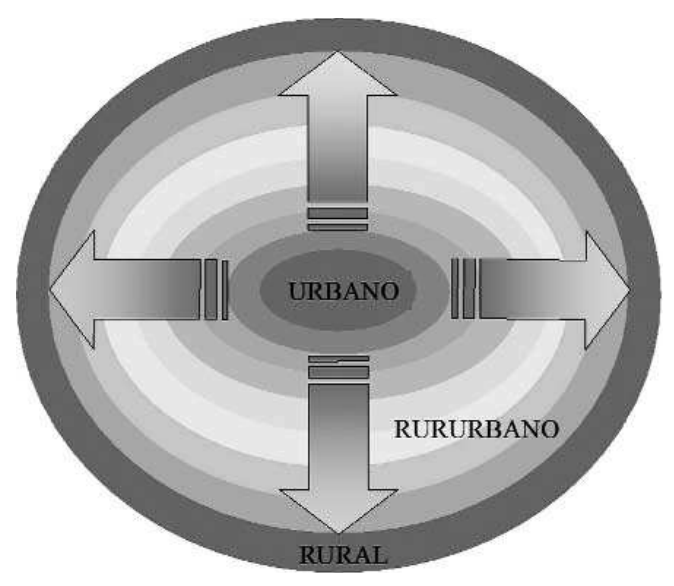

1. Esquema expansión urbana.

vemos es un paisaje en mosaico, con restos y pervivencias de otros anteriores. Dicho en palabras de Martínez de Pisón: "El paisaje se formaliza necesariamente sobre un sistema territorial, es no sólo la visión de una forma geográfica sino esa misma forma. Pero el paisaje no es el territorio. Este consiste en el espacio-función, el solar, la base geográfica manipulable y su expresión administrativa. El paisaje es la configuración morfológica de ese espacio básico y sus contenidos culturales; en ese sentido es una categoría superior al fundamento territorial. La condición cultural del paisaje es su misma sustancia, lo que permite su asimilación a tal trasfondo, lo que da lugar a que pueda residir en él la identificación de un pueblo"2.

La ausencia de una "mirada" capacitada para apreciar el valor cultural del pai$\mathrm{saje}^{3}$ se manifiesta en la consideración que de éste se hace tanto en aplicación de la legislación urbanística como de la propia legislación de patrimonio. En cualquier caso, ninguna de esas dos legislaciones deja mucho margen -siendo generosos- a la protección efectiva del patrimonio desde un punto de vista integrado.

La dialéctica rural / urbano se plantea en la legislación urbanística de modo que el primero constituye un residuo marginal y subsidiario del segundo por efecto de la urbanización. Así, el medio rural es propiamente rurubano en mayor o menor grado [1], y sobre él se delimitan, planificaran -literalmente, sobre el plano- las zonas afectadas por la urbanización y los usos futuros.

La idea de marginalidad y subsidiariedad de cualquier tipo de suelo, de cualquier tipo de uso frente al urbano y a la urbanización está implícita, cuando no explícita, en toda la legislación urbanística de los últimos treinta años, por no remontar-

y Juan Agudo Torrico las observaciones y críticas que en su dia hicieron a aquel trabajo.

2 MARTÍNEZ DE PISÓN (1997) "El paisaje, patrimonio cultural”, Revista de Occidente n¹94-195 (JulioAgosto 1997), pág. 37

3 MARTÍNEZ DE PISÓN (1997) op. cit., pág. 41. 
nos más. Así, la Ley 7/2002 de Ordenación Urbanística de Andalucía en su Art. 2 establece que "la actividad urbanística es una función que comprende la planificación, organización, dirección y control de la ocupación y utilización del suelo, así como la transformación de éste mediante la urbanización y la edificación y sus consecuencias para el entorno." Luego añade que "la actividad urbanística se desarrolla en el marco de la ordenación del territorio", pero lo que se colige de la definición previa es la idea imperante de que no hay más ordenación del territorio que la urbanización ${ }^{4}$, y los hechos no lo desmienten.

Sin embargo "pueblo" no es igual a "ciudad", por emplear unos términos que entendamos todos. El medio de vida en uno y otro no es el mismo -al menos hasta ahoray, consiguientemente, la relación con el entorno, su modulación y proyección, no son tampoco las mismas. Es, además, una cuestión de escala, esencial a corto y medio plazo, ya que los cambios de ésta van a tener consecuencias cuantitativas y cualitativas.

La urbanización del medio rural -y el rurbanismo como resultado- supone una extensión espacial del proceso de urbanización periurbana hasta áreas más distantes del centro urbano de influencia. Representa según Cadène ${ }^{5}$ la instalación en colectividades rurales de individuos originarios del medio ciudadano, que conservan su actividad profesional ciudadana, provocado por un exceso de concentración de la ciudad o por un deseo de estándares de vida -más "auténticos" y "tradicionales"- promovidos, complementados y no satisfechos por la ciudad. Para algunos autores esta urbanización es básicamente un proceso de aculturación ${ }^{6}$ dirigido desde la ciudad al campo ${ }^{7}$ que implicó, a través de la desolidarización con el medio, de la reivindicación de un "trabajo" profesional y de la devaluación del producto agrícola, una ruptura con la actividad profesional y con el medio, y tuvo como último resultado el éxodo rural. Y es el lugar dejado por este 'éxodo' de los sesenta el que ocupa [okupar es otra de las expresiones de la urbanización, de signo bien diferente] una nueva población "rural" 8 . A esta situación hay que añadir en Andalucía el impacto del Plan de Empleo Rural, y de la política agraria comunitaria.

Ante esta situación se han dado principalmente tres alternativas para la población rural. La primera, continuar la práctica agrícola tal cual, lo que supone a medio plazo la desaparición de la actividad. La segunda, abandonarla pasando a

\footnotetext{
4 También esa ley establece la "novedosa" categoría de "Hábitat rural diseminado" como suelo no urbanizable, que parece dirigido a proteger los ámbitos que tratamos. Simplemente mirando por la ventanilla al circular por cualquier carretera andaluza podemos observar la aplicación que ha tenido.

5 CADĖNE, F. (1980): “L'usage des espaces pèri-urbains. Une géographie régionale des conflicts", en Études rurales, pág. 237.

6 RAMBAUD, P. (1966) “Le travail agraire et l'evolution de la société rural” en. Études rurales, 22-23-24, pág. 160.

7 RAMBAUD, P. (1973) “Village et urbanisation. Problèmes sociologiques”, en Études rurales, 49-50, pág. 14.

8 CRIBIER, F. (1973) "Les résidences secondaires des citadins dans les campagnes françaises". en Études rurales, 49-50. pág. 185.

9 RAMBAUD, P. (1966) op. cit., pág. 172.
} 
buscar otro trabajo, lo que significa una mutación (entendida como cambio drástico, cuyo origen y resultado escasamente tiene que ver con lo anterior). La tercera, continuar la actividad modificando ciertos aspectos, lo que se puede camuflar más o menos como cambio adaptativo, aunque "¿se puede aún hablar de sociedad rural cuando la imagen que elabora del trabajo y de ella misma, y las actitudes que desarrolla son cada vez más importadas?"9.

Campo y ciudad son dos tipos de espacios creados por una sociedad en función de las implicaciones de su sistema económico y cultural, de las prerrogativas acordadas por su poder político, o sus voluntades concernientes al urbanismo ${ }^{10}$. Algunos autores han visto el conflicto entre el campo y la ciudad como un conflicto de clases, sin que éstas sean clase urbana y clase rural, ya que en la sociedad rural también existen clases. Es esa clase media-alta rural la que fácilmente se asimiló a la clase media urbana, mientras la clase baja rural, la del suburbio urbano o la que permanece en el pueblo, acaba haciendo suyos los estereotipos rururbanos: adaptando los elementos rurales descontextualizados escogidos e impuestos como emblemáticos por la urbanización ${ }^{11}$ de modo inevitable: "lo que se presente como dominante ante el público, acabará siendo reforzado como dominante por la propia acción de ese público"12. Por otro lado, en nuestro contexto, el rechazo a "lo antiguo", el deseo de cambio, de modernización, no puede entenderse sin la pobreza material que otros tiempos significaron.

Así, los modelos de planificación urbanística no se pueden / deben aplicar como plantillas al medio rural. Lo contrario sólo puede responder a intereses concretos y ajenos al medio, o sea, urbanísticos. Ya se trate del agua ${ }^{13}$ o del suelo "los planes de ocupación (...) y demás actuaciones administrativas son opciones políticas que tratan de conjugar diversos intereses especialmente económicos, entre grupos de desigual fuerza"14.

La protección del patrimonio está legalmente ligada a la legislación urbanística y por tanto al concepto de inmueble. Ya se trate de monumentos como del paisaje mismo, se abordan con unos procedimientos técnicos que parten de la normativa urbanística, como ya se recomendaba en la Carta de Ámsterdam de 1975.

En los últimos años, el cambio de enfoque de la protección orientándola hacia el marco de ordenación del territorio, que supone el uso de la planificación urbanística como instrumento de control, no parece que haya representado un gran cambio, a pesar de lo que dice la nueva vieja Ley 14/2007 de Patrimonio Histórico de

10 RAMBAUD, P. (1973) op. cit.,. Études rurales, 49-50, pág. 18.

11 GARCÍA DE LEÓN, M.A. (1996) "El rurbanismo o las transformaciones del campo español". Fundamentos de Antropología, 4-5, págs. 221-229.

12 AGUILAR IDÁÑEZ, J.M. (1992): "Lo rural, lo urbano, la prensa y la gente". GARCÍA DE LEÓN, M.A. [et. al] (1992) La ciudad contra el campo. Sociedad rural y cambio social. pág. 239.

13 COMPÁN VÁZQUEZ, D.; FISCHER, J. y JIMÉNEZ BAUTISTA, F. (1995) "La sectorialización del espacio geográfico. Impactos de la política hidráulica en la dialéctica campo-ciudad”, Boletín de la A.G. $E_{.} n^{\circ} 20$, págs. 39-54.

14 RAMBAUD, P. (1973) op. cit., pág. 26 
Andalucía. Como mucho, se llegan a considerar 'bien a proteger' el continuo arquitectónico y (sólo sobre el papel) la relación de éste con el área territorial a la que pertenece, incluyendo en el ámbito de protección los accidentes geográficos y parajes naturales que conforman su entorno. Pero raramente se llegan a considerar otros aspectos socioeconómicos o históricos sobre la génesis, pervivencia y transformación del paisaje relevantes para su interpretación, conservación y mantenimiento.

La tutela del patrimonio en ese contexto se reduce a la de algunos elementos inmuebles "emblemáticos" -de orden artístico-monumental, generalmente-. En la práctica, se niega el reconocimiento de bien integrante del patrimonio histórico/cultural de cualquier otro tipo de bien que no se considere equiparable a aquellos. Así sucede con los usos, con el sistema de explotación del medio, y con las construcciones que éstos han generado, a pesar de tener, en la mayoría de los casos, más peso histórico y cultural que aquellos, ya que son los que permiten interpretarlos en su integridad.

El patrimonio cultural en el medio rural, constituido e inmerso en un entorno en el que el uso tiene una especial relevancia en la creación y mantenimiento del mismo, tiene que ser objeto de conocimiento y protección, siendo el objetivo fundamental de éstos el de evitar la pérdida de un aspecto imprescindible de la comunidad, como son los elementos que conforman su identidad. Los cambios, las mutaciones de la sociedad, se manifiestan con sus caracteres plásticos, su utilización y su significación en el espacio ${ }^{15}$. Pero con frecuencia se ofrece el espacio como contenedor -estético, naturalmente- con relación a sus contenidos, relegando su realidad como campo de relaciones sociales y de producto de esas relaciones sociales mismas.

La urbanización transforma -y copia- el urbanismo rural anterior privándolo de sus funciones primarias ${ }^{16}$. Esta urbanización de los pueblos, correlativa -inevitable en el esquema- a la de las ciudades, con frecuencia se presenta con la configuración de residencia secundaria y con la introducción del "sector servicios" en general ${ }^{17}$. Así, los cambios en la estructura productiva, y por ende cultural, van a ser tan drásticos como con cualquier otro modo de urbanización -con la implantación de industria, por ejemplo-. Eso sí, la estética quedará mejor preservada. Así, el espacio se constituye en objeto de valoración social, de la misma manera que antes lo fue de desvaloración.

Repasando la normativa y recomendaciones internacionales, encontramos que en la mencionada Carta de Ámsterdam (1975) se señala una línea de trabajo que se apoya en "una lectura de los conjuntos urbanos y rurales, sobre todo en la estructura, sus funciones complejas, [el subrayado es mío] así como las características arquitectónicas y volumétricas de los espacios abiertos", corrigiendo así el enfoque por el cual "el análisis de lo social, de las relaciones sociales y del propio componente afectado, aparece relegado como algo subsidiario en relación a la piedra"18.

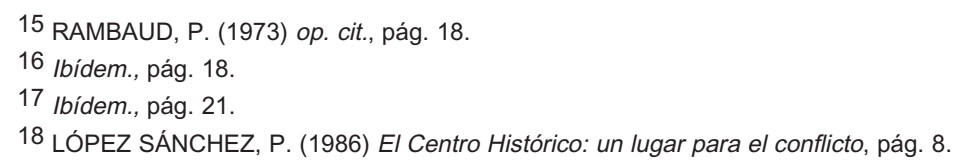


En definitiva, en palabras de López Jaén 19 "el objetivo mismo de la conservación no es el simple mantenimiento de unas estructuras físicas dadas o los beneficios que su uso pueda acarrear, sino en cuanto a la salvaguarda y recuperación de formas de vida más acordes con el medio, y por su capacidad de equilibrar el desfase entre las tecnologías tradicional y moderna y la alienación que la imposición de ésta última ha supuesto hasta el momento".

En la Carta del Restauro (1987) la conservación de los BB.CC. se entiende como la paliación de los procesos degradantes. Al contrario que en la Carta de Atenas (1931), se hace hincapié en la necesidad de primar el análisis y la protección sobre los aspectos estructurales en vez de en los visuales, como se había venido entendiendo en documentos anteriores. La Carta de Riesgo (1991) aporta como nueva consideración la necesidad del estudio de las condiciones ambientales (naturales o antrópicas), así como la conservación preventiva.

La Ley de Patrimonio andaluza reconoce, además de los inmuebles y muebles, de las actividades que se consideren como elementos integrantes del Patrimonio. Pero de ese tema20, poco más se ha sabido.

\section{LOS CASOS.}

Los dos lugares objeto de análisis que propongo han sido reconocidos desde hace casi medio siglo -en un caso- y un cuarto de siglo -en el otro-, por diferentes administraciones debido a la conservación de sus valores paisajísticos, que se estimaban representativos de la 'cultura tradicional'. Precisamente por este reconocimiento han ejercido una cierta influencia como modelo a imitar en otras poblaciones. Paradójicamente, este carácter ejemplar también se manifiesta en los exiguos resultados obtenidos.

Estos valores paisajísticos consistían en el mantenimiento de una estructura urbana, unos tipos arquitectónicos, así como una articulación singular del conjunto con su entorno, a partir de unas formas de vida a las que se les suponían hondas raíces históricas.

Estos lugares basaban una parte importante de su producción económica en la agricultura, en la que el modo de explotación se fundamenta en un hábitat en ladera con articulación vertical de las diferentes áreas del espacio productivo. En la proximidad de los núcleos y a menor altitud que éstos, se localiza el área principal de cultivo intensivo sobre terrazas irrigadas artificialmente mediante un vasto, complejo y sofisticado sistema hidráulico, en el que el agua se contempla como activo social21 principal.

19 LÓPEZ JAEN, P. (1987) Normativa intenacional. Curso de rehabilitación, vol. 0. Colegio Oficial de Arquitectos de Madrid.

20 RIOJA LÓPEZ, C. (1996) "Reflexiones en torno a la cultura inmaterial y su gestión patrimonial en la Comunidad Autónoma Andaluza". Boletín del Instituto Andaluz del Patrimonio Histórico, 16, págs. 73-78.

21 AGUILERA KLINK, F. (1994) "El agua como activo social”, en GONZÁLEZ ALCANTUD, J.A. y MALPICA CUELLO, A. (eds.): El Agua: mitos, ritos y realidades,. págs. 369-374. 
El sistema hidráulico consiste en una red de elementos de captación, almacenamiento y distribución de agua captada en lugares donde la hay y conducida mediante acequias a las zonas idóneas para el cultivo, en las que no se dispone de aquella, con un sistema de reparto de importante significación social. Para algunos autores, esta práctica de cultivo está más próxima a la jardinería que a la agricultura. También forman parte del sistema otros elementos añadidos, susceptibles de diferentes usos, como molinos, fuentes, terrazas artificiales para cultivo, albercas, caminos, etc.

Las terrazas artificiales a base de muros de mampostería seca que permiten adecuar el terreno a un cultivo agrícola muy particular, tienen amplia tradición cultural en Andalucía -como técnica agrícola se conoce desde la Edad del Cobre-, y en conexión con este sistema particular de disposición y distribución del agua y una determinada forma de asentamiento, constituye un elemento cultural de tradición medieval, mantenido hasta nuestros días con entidad propia.

Por lo general, algunos de estos elementos son considerados de interés, siempre de forma aislada, sin reparar en que en su configuración sistémica, tanto infraestructural como social, radica su principal valor patrimonial, y que no es posible la interpretación de elementos individualizados sin atender a aquélla.

Puestos a clasificar estos lugares como bienes culturales, se les podría aplicar el tipo de Monumento, Zona Arqueológica, Sitio Histórico, Jardín Histórico, Lugar Etnológico, Zona patrimonial; cualquiera de ellos sería apropiado.

\subsection{FRIGILIANA.}

En el caso de Frigiliana se puede ver la irrelevancia de la figura de protección cuando hay determinación de hacer efectiva su tutela. Así la figura de Paraje Pintoresco ha servido para mantener una trama urbana y un perímetro del caserío en los límites en que fue definido. Lo que no estaba establecido, como las alturas de la edificación y la relación con el entorno y los bienes que constituyen éste, ha sido despreciado.

Frigiliana 22 es uno de los pueblos de la provincia de Málaga que más galardones ha recibido, resultado, entre otros factores, de la política municipal de "embellecimiento"23 apoyada en sus valores culturales que desde los años sesenta [2] fue dirigida a la promoción turística de la localidad. Tras un intento de incoación de expediente de protección como Conjunto Histórico-Artístico, a mediados de los años setenta fue incoado expediente como Paraje Pintoresco para una parte del núcleo, el denominado en la documentación administrativa "barrio morisco-mudéjar"24 [3].

22 Según el Instituto de Estadística de Andalucía, el municipio tenía 2978 habitantes en 2008.

23 En 1982 obtuvo el Primer Premio Nacional de embellecimiento y mejora de los pueblos de España.

24 Según consta en la documentación que obra en la Delegación Provincial de Cultura relativa a La Villa de Frigiliana. Conjunto Histórico-Artístico [P-4 n 60] y al Paraje Pintoresco de Frigiliana [l-1 n 7], con fecha 3 de diciembre de 1965 la Dirección Gral. de BB.AA. incoa expediente de declaración de Conjunto Histórico- 


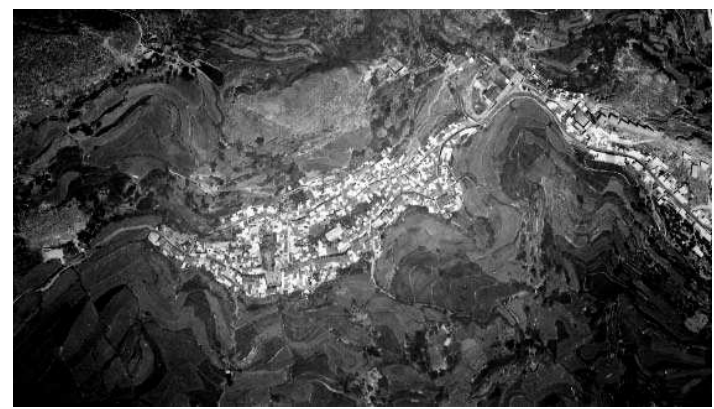

3. Frigiliana delimitación año 1982.

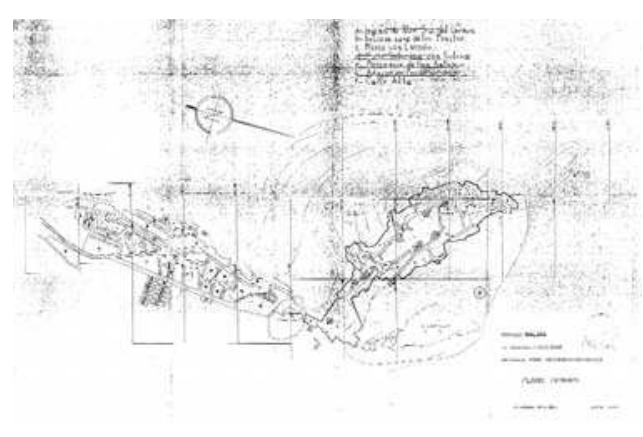

Desde entonces, las intervenciones en el casco urbano han tenido algunos resultados indudablemente beneficiosos, como ha sido el mantenimiento de la estructura viaria del 'Barribarto' y del 'Barribajo', con muchos de sus adarves, pero también ha tenido efectos negativos, como la "estandarización pintoresca", que crea una variedad decorativista en absoluto tradicional, y una concepción museística del pueblo -que se encargan de recordárnosla los azulejos ${ }^{25}$ que ilustran las esquinas

Artístico de la Villa de Frigiliana. Posteriormente, y con fecha 26 de marzo de 1973, la misma Dirección General deja sin efecto dicha resolución, sin que consten en el expediente las respectivas publicaciones. El 15/3/1976 (BOE n¹31, 1/6/1976) se incoa expediente como Paraje Pintoresco de Frigiliana por iniciativa de la Dirección General de Patrimonio Artístico y Cultural, aunque sin estar definido. Desde entonces hay un continuo cruce de cartas entre el Ayuntamiento, que argumenta falta de medios técnicos y económicos para elaborar la documentación que le ha sido requerida, la Delegación provincial y el Ministerio o la Consejería -desde el traspaso de competencias-, y un plano de delimitación de 1982. Sin embargo, en el listado de expedientes en trámite de declaración seguía apareciendo el relativo al Conjunto Histórico-Artístico de Frigiliana, y en cada intento de aclaración de la cuestión se exhorta a que "en caso de no existir expediente de declaración de CHA a favor de Frigliliana, debería procederse a la incoación del mismo". Tras más de tres décadas de confusión, el expediente de Paraje Pintoresco no ha sido terminado ni cerrado, ni el de Conjunto Histórico-Artístico fue iniciado.

25 Sin que esto signifique negar en modo alguno su indudable valor artístico. 
con sus crónicas históricas- y el empedrado artístico.

La trama viaria se configura en dos calles casi paralelas, a diferente altura, que siguen las curvas de nivel, describiendo la forma longitudinal del núcleo, como son la calle Alta y la calle Real, que luego se prolonga en la calle Chorruelo. Para algunos autores, a lo largo de la calle Alta se extendería el primer caserío de Frigiliana, pero no hay datos concretos para apoyar esta afirmación. Enlazando estas dos calles discurren otras en el sentido de la pendiente, de las cuales todas -excepto una- son adarves, algunos de ellos cegados. El resultado es una trama orgánica, de grandes manzanas entre las dos calles principales, mientras en los bordes las manzanas se alargan siguiendo la topografía entre la calle principal y el monte, en la parte alta, y los bancales, en la parte baja.

Topográficamente el pueblo queda enmarcado entre el Peñón de la Sabina o de Frigiliana, por un lado, y por otro con el Peñón de la Batalla y los "Tajos coloraos", el río Higuerón y "la zona abancalada que desde los muros de Frigiliana se extiende hasta el río, convertidos en fértiles huertas desde época medieval" 26 , esto es una zona de monte, limitada por el casco, y las terrazas de cultivo. Sobre estos tres ámbitos, conectándolos, se traza, desde época medieval, el sistema hidráulico -del que forman parte también los bancales, las acequias, las albercas, los molinos, los caminos que comunican éstos-, elemento representativo de la actividad económica -agrícola y protoindustrial-, que rodea y cruza el pueblo.

El conjunto compuesto por fuente-castillo-huerta/vega/bancales-alquería que en torno al siglo $X$ denota un nuevo patrón de asentamiento27, está presente en Frigiliana. A destacar entre esos elementos el sistema hidráulico de Lisa, compuesto por el molino hidráulico harinero, el "Pozo", y la acequia de Lisa, ya descrita por Mármol, que pasa ${ }^{28}$ al pie del peñón [del Castillo]; y el sistema hidráulico de El Chorruelo, con la acequia homónima que recorre gran parte del pueblo, asomando en cuatro o cinco ocasiones, tanto en la calle del mismo nombre como a lo largo de su recorrido, y alimenta la Fuente Vieja, situada en el centro del pueblo. Otra acequia que también cruza el casco es la de Santo Cristo, que pasa junto a la ermita del mismo nombre. El límite sur del pueblo lo marcan una sucesión de bancales de cultivo escalonados que dan nombre al lugar: pago/sector de los Bancales.

De época moderna y contemporánea hay un conjunto de edificaciones industriales que han delimitado históricamente el caserío en el espacio comprendido entre las principales estructuras productivas -que no eran compatibles con la habitación-, que son el Ingenio y las Maquinillas -al Este- y el molino de aceite de Frasquito Platero -al Oeste-. Otro límite exterior a aquel era el que marca el inicio de los cami-

26 AGUILAR GARCÍA, M.D. [et. al.], (1985). Inventario Artístico de Málaga y su provincia. vol. I, pág. 303.

27 DELAIGUE, M.C. (2006).- "Évolution du peuplement dans le district de Vélez-Málaga: prolégomènes". Mélanges de la Casa de Velázquez, tomo 36-1, págs. 357-366.

28 Cressier asemeja este dato con lo que observa en Dalías. CRESSIER, Patrice [et. al.], 1992 :111 relaciona . "Dalías y su territorio: un grupo de alquerías musulmanas de la Baja Alpujarra". Estudios de Arqueología Medieval en Almería. 
nos a Nerja -y Málaga- y a Torrox -y Granada-, como son las ermitas, de San Sebastián, al Este, y del Santo Cristo, al Oeste.

El municipio tenía en 1969 Plan General de Ordenación, que fue sustituido por las Normas Subsidiarias de 1985 (achacado a que en el plan no se había previsto el crecimiento luego experimentado), reemplazadas a su vez por la Revisión de las Normas Subsidiarias de 1999. En la actualidad se está redactando un nuevo Plan General de Ordenación Urbana.

El objetivo de las NN.SS. de 1985 era el crecimiento económico basado en el turismo, salvaguardando la zona de regadío y la estética del núcleo, y la mejora de las comunicaciones, a partir de la "preservación de los valores del conjunto del casco en la forma más óptima posible"29. Para ello se expresa que "importante medida sería la incoación de expediente para la declaración de conjunto histórico-artístico del casco antiguo de Frigiliana, ya que supondría un control importante sobre el desarrollo futuro de la renovación del caserío urbano, necesaria dada las características de pequeñez y falta de instalaciones de las viviendas" 30 .

Se traza un nuevo borde "funcional": el ensanche en la zona de los Bancales; pero, sabiendo del fuerte impacto que sobre el núcleo tendrían las nuevas construcciones, se propone concentrar la edificación en la parte baja de esa zona, junto a la carretera de circunvalación ${ }^{31}$ [4], buscando también la protección del uso agrícola32. Por ello, un $10 \%$ de los casi $40.000 \mathrm{~m}^{2}$ que comprendían los Bancales y el Chorruelo son declarados 'no urbanizables' [5].

El proyecto de urbanización de Los Bancales fue desarrollado en un Plan Parcial de Ordenación presentado a la Comisión Provincial de Urbanismo en 1992. Rechazada la primera propuesta, fue aprobado definitivamente en 1993, estableciendo un número total de 330 viviendas a construir -con parámetros de superficie útil tipo VPO-; esto es, el triple de las establecidas en las NN.SS. 1985. Curiosamente, en el informe visado del Colegio de Arquitectos de Málaga se hace notar que no está suficientemente justificada la consideración como suelo urbanizable consolidado ${ }^{33}$.

\footnotetext{
29 NN.SS.1985:31

30 NN.SS.1985:31

31 NN.SS.1985:18 "[...] la expansión que se prevé entre el caso antiguo y la carretera de circunvalación ya trazada se propone con las mismas densidades y características edificatorias que el propio casco antiguo. Creemos que hay que distinguir entre una postura de respeto hacia lo existente y otra basada en una actuación mimética, de imitación formal de lo existente, pueda en el fondo ser menos respetuosa con los valores que se pretende conservar. Esta ampliación del casco urbano creemos que dañaría fuertemente su imagen exterior, además de los afectos que podría producir sobre aquel, ya que de ser un núcleo que tiene fuertemente acentuado su condición de aislado pasaría a ser el centro de uno mayor. Para salvaguardar esta imagen [...] se propone la concentración de la nueva edificación en la parte baja, ligada directamente a la carretera de circunvalación, y el mantenimiento de una franja no edificada que, dada la diferencia de cota existente entre la carretera y las edificaciones del casco establecería un corte entre dicho casco y las nuevas actuaciones, de forma que las nuevas construcciones se yuxtapongan con el casco antiguo, marcándose la imagen de núcleo que actualmente tiene este". NN.SS. 1985:27 "[...] el casco antiguo está perfectamente definido y no admite expansiones en sus bordes por las dificultades del terreno".

32 NN.SS. 1985:24 "en los regadíos que rodean al casco antiguo se prohíbe la edificación para proteger el uso agrícola y a la vez los valores paisajísticos de los alrededores del casco urbano /...l".

3323 julio 1992 "[...] el Expediente no aporta justificación concreta que acredite que a partir del estado actual de consolidación y urbanización de los terrenos sea posible reclasificarlos directamente como suelo urbano".
} 


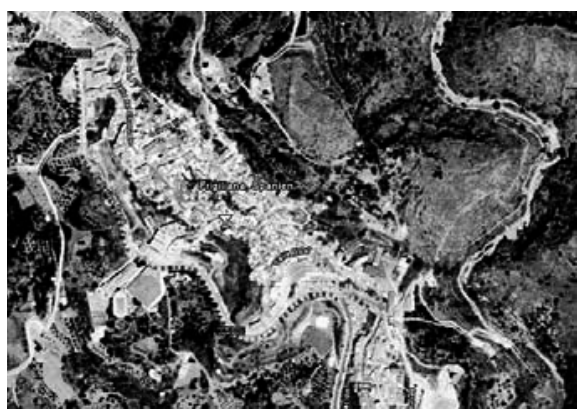

4. Frigiliana 2004 - Google.

5. Frigiliana 2009 - Expansión hacia el sur.

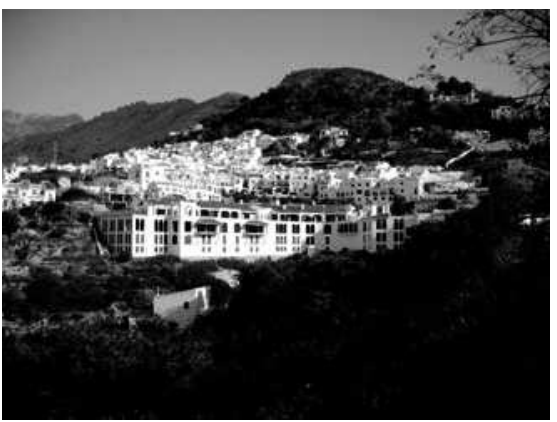

Paralelamente se empezó a redactar una Revisión de las Normas Subsidiarias -el Avance fue aprobado en 1994, y la aprobación definitiva se hizo en 199934 cuyos objetivos eran: corregir irregularidades en la urbanización de terrenos calificados como "no urbanizables", y dotar al pueblo de una vertebración urbana, de la que carecía a juicio del autor de la Revisión ${ }^{35}$, así como de nuevo suelo para equipamientos y viviendas en el casco viejo que "favorezcan el desarrollo y el confort del uso turístico de Frigiliana", que para entonces estimaba había perdido ${ }^{36}$. Para ello se proponía modificar el Plan Parcial de los Bancales, abriendo ("hacer permeable") el casco viejo hacia el sur, y "completando" ciertos espacios actualmente con uso agrícola o "sin uso alguno" [6].

34 Con modificaciones en 2001.

35 R.NN.SS. Avance 1994 "[...] así como en la mayoría de los pueblos de similar nivel que Frigiliana tienen definido un "centro urbano que en la mayoría de los casos suele coincidir con la habitual "plaza" de carácter institucional (Ayuntamiento, Iglesia, Bancos, comercios, etc.) este fenómeno no se produce en el pueblo que nos ocupa. No existe definido un "centro" urbano como tal, sino tan solo una centralidad difusa coyunturalmente puntualizada a determinadas horas. El hecho de existir dos áreas diferenciadas (casco antiguo y nuevo) acentúa esa falta de un área en donde se ubique el máximo de relaciones sociales y comerciales".

36 R.NN.SS. Avance 1994 "[...] la tendencia residencial hacia la zona de extensión de Frigiliana ha hecho que el bello casco antiguo carezca de atractivo para la vivienda actual. Esa tendencia ha de ser cambiada haciendo dicha zona más confortable en todos los sentidos. [...] en ese sentido se introducen en dicho Plan [Parcial de los Bancales] algunas modificaciones que mejoran la dotación de aparcamientos, la permeabilidad del espacio urbano y la puesta en uso de áreas libres". 


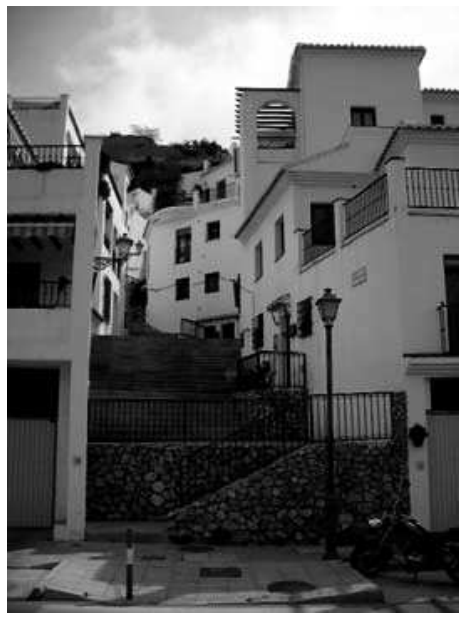

6. Frigiliana 2009 - "Hacer permeable".

Es obvio que estas apreciaciones parten del desconocimiento del proceso histórico que conforma Frigiliana, de una concepción de la ciudad reducida al urbanismo central y ortogonal, y falta, además, de imaginación. En definitiva, se consideran los bancales como elemento accesorio en la configuración histórica y paisajística de Frigiliana, en lugar de producto de la misma cultura, de las mismas raíces que la arquitectura vernácula que los haría merecedores de la consideración de idéntica entidad cultural que aquella. Al introducir dichas modificaciones, la relación entre extensión del hábitat / extensión del área productiva agrícola contigua -los bancalesse vería profundamente afectada, con lo que a efectos de valoración paisajística esto supone. La protección del paisaje se reduce a proponer la imposición de una serie de "servidumbres de vistas" que permitan su contemplación "desde la carretera de Nerja", como allí se dice. No obstante, se seguía insistiendo en la importancia del valor cultural de ese paisaje y en la necesidad de protegerlo37.

No había ninguna limitación para la urbanización de los Bancales, ya que la delimitación del Paraje no afecta más que al conjunto arquitectónico, al caserío. En 1994 la administración cultural encarga un trabajo de análisis ${ }^{38}$ dirigido a determinar el interés de continuar con los procedimientos de protección incoados o propuestos. Es

37 R.NN.SS. Avance 1994 "En la actualidad el valor turístico y el atractivo de Frigiliana radica en su personalidad paisajística y arquitectónica que se basan en su topografía, en la 'textura' del medio físico y en su singularidad arquitectónica, fruto no solo de las raíces históricas sino de su adaptación al terreno [i!]. Sin embargo todas esas singularidades se han mantenido fruto de las circunstancias no claramente voluntarias y a veces motivadas por la fragilidad de las economías domésticas. Es por eso que la menor presencia de esas circunstancias en el área urbana más reciente ha producido un resultado arquitectónico de menor valor. Se echa de menos una herramienta legal que proteja ese rico patrimonio de Frigiliana y que una vez perdido (como en tantos pueblos de la Axarquía) carecerá de interés cualquier fomento de visitas turísticas".

38 Ese trabajo, "Análisis de centros históricos susceptibles de incoación como Conjunto Histórico en la provincia de Málaga. Frigiliana. 2005", fue hecho por quien redacta este texto. En aquel tiempo, en el Ayuntamiento de Frigiliana no se me permitió ver más que las NN.SS. de 1985 y la memoria del Avance de la R.NN.SS. 
7. Frigiliana - Vistas al Jardín Botánico.

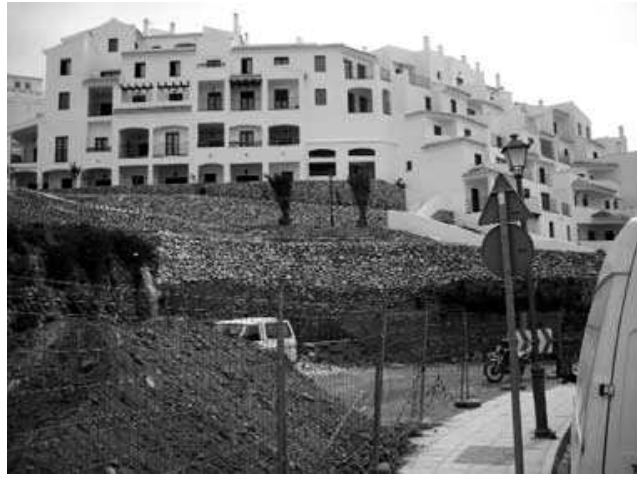

entonces cuando se destaca el valor de los Bancales no ya como mero 'entorno' del conjunto, sino como bien con significación propia y elemento fundamental que hace posible la interpretación del conjunto. Pero para entonces ya era $\operatorname{tarde}^{39}$ [7].

La carretera de circunvalación, justificada como nuevo límite, sirvió, como en cualquier ciudad, para saltárselo. El entorno del Ingenio se urbaniza. La nueva edificación se extiende también por la falda del castillo y el entorno de Liza. Y como el 'jardín histórico' por excelencia de Frigiliana 'se perdió', en la reserva de suelo para zonas verdes de esa nueva área urbana de Los Bancales se establecía, naturalmente, la construcción de dos jardines, 'el Portón' y el 'Jardín Botánico’40 [8].

\subsection{El Genal.}

En el caso del valle del Genal, catorce pueblos (obviando Gaucín) de muy pequeño y pequeño tamaño ${ }^{41}$ se reparten por una amplia extensión de accidentado terreno. Aquejado de la depresión económica y poblacional de las zonas de montaña, la proximidad a la Costa del Sol y al Campo de Gibraltar lo convierten en una potencial área de expansión residencial apoyada en sus valores paisajísticos. Atendiendo precisamente a esos valores se determinó hace un cuarto de siglo redactar una normativa urbanística conjunta, que no se llegó a hacer. Los intentos

\footnotetext{
39 A pesar de ello, incluso años después, en el Catálogo que para la Revisión de las NN.SS. hace en 1998 una empresa de consultoría patrimonial, se recogían los Bancales como uno de los bienes culturales del municipio. También figura así en el Catálogo del Avance del PGOU de 2006.

40 En verano de 2008, Diario SUR bajo el titular "Frigiliana pide un préstamo de 100.000 euros para terminar un jardín botánico", publica que "el futuro jardín botánico y la plaza de ocio de Frigiliana estará en la zona de Los Bancales, junto al pabellón cubierto. [...] Ocupará 6.200 metros cuadrados, con plantas autóctonas y una instalación de gimnasia para la tercera edad. [...] Hasta ahora se han invertido 225.000 euros. El Consistorio ha pedido un crédito de 100.000 para terminarlo. [...] Está previsto que el nuevo recinto se inaugure en 2009."

41 De cerca de 160 habitantes a poco más de 1000. En total, unos 6500 habitantes en casi $390 \mathrm{~km}^{2}$.
} 


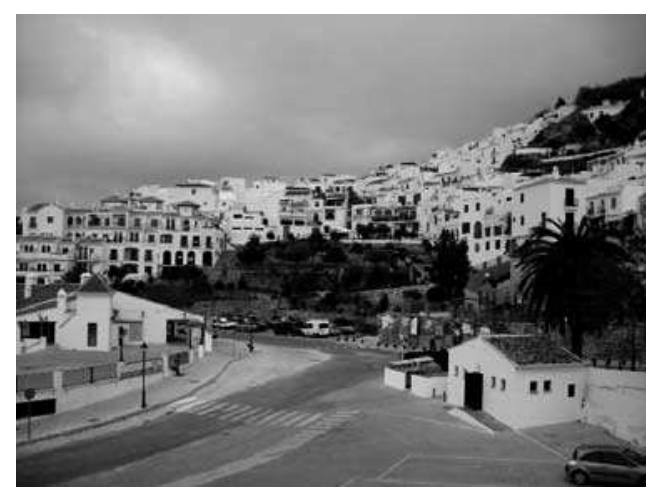

8. Frigiliana - La reserva verde de "El Portón".

individualizados de protección tampoco tuvieron efecto alguno. Una nueva normativa con planteamiento común y desarrollo individualizado, actualmente en redacción, adolece de los mismos defectos de siempre: ignorar el carácter integrado del patrimonio y destacar elementos singulares con efecto decorativo.

La grandiosidad del paisaje de secano, esencialmente arborícola -a base de castaños, morales, higueras y zumaque-, junto con el monte mediterráneo, domina en el valle del Genal. Los cultivos de secano, y su abandono, se revelan en el paisaje por la presencia de dos estructuras construidas: las terrazas y las eras. Su valor radica tanto en el interés histórico, como testimonio de una producción que tan importante fue en la economía comarcal, como en su interés medioambiental.

El paisaje del hábitat disperso, de chozos, bodegas y alquerías, reunía valor productivo y habitacional, correspondiendo a una explotación agrícola y/o ganadera, con escaso impacto en el entorno. Sus restos, abandonados y arruinados, están siendo suplantados en la actualidad por construcciones de nueva planta con marcado uso secundario-residencial, fuerte impacto visual y mayores demandas y consumos ambientales, del mismo modo que podríamos decir, en términos generales, para la vivienda en los núcleos de población.

En los pueblos, las iglesias parroquiales -que en su mayor parte datan del siglo XVI- unen a su valor simbólico como centros de religiosidad, el de constituir el tipo más numeroso de edificación monumental que es, además, referente principal en la trama histórica de los núcleos, aunque ya no se distingan en el perfil urbano con tanta facilidad como antaño: son frecuentes los casos en que las nuevas casas superan con creces la altura de las iglesias. Los cementerios estuvieron junto a las iglesias hasta que en el siglo XIX fueron construidos otros nuevos en el borde de las poblaciones. Las ermitas y capillas, esencialmente lugares de culto religioso de menor rango canónico que las iglesias, tienen una importante significación social -que se muestra especialmente en las fiestas y celebraciones- y simbólico-territorial de diversa escala -de local a supralocal- como hitos y marcadores del espacio. 
9. Fuente Nueva de Parauta.

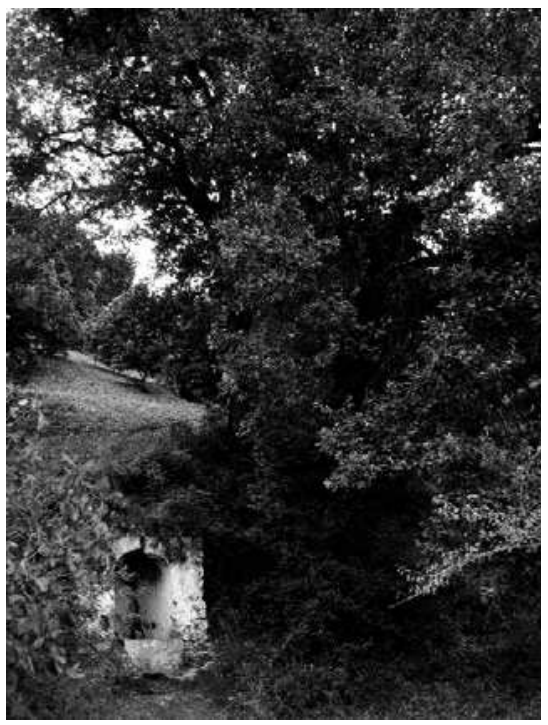

Igualmente, los calvarios, las cruces y los humilladeros tienen valor religioso y también significación territorial.

Otros hitos urbanos principales son los relacionados con actividades de subsistencia y, especialmente, las fuentes, que no sólo han sido lugares de abastecimiento cotidiano, sino también, como aquellos de carácter religioso antes referidos, lugares de sociabilidad por excelencia, adonde acudían las vecinas -principalmentea llenar los cántaros. Realmente se trata de aljibes con bóvedas trasdosadas que recogen y almacenan el agua de un venero para abastecimiento humano. Cada barrio de cada núcleo de población dispone de al menos una fuente que, por lo general, está asociada a un lavadero y un abrevadero, formando un conjunto en el que, o las tres partes se yuxtaponen, o bien se distribuyen próximas en el espacio inmediato. Por lo general, están situadas en el borde de los barrios, aunque suele haber otra fuente en la plaza principal. Aún mantienen, parcialmente, el carácter de puntos de sociabilidad en razón de su ubicación, especialmente las situadas en el centro del pueblo, aunque su valor subsistencial haya pasado a un segundo plano [9].

Sin duda, uno de los principales paisajes del valle del Genal es el de cultivo de regadío en terrazas, el de las huertas, el de las vegas, que -sin embargo- ha pasado desapercibido para muchos. Así, el geólogo Orueta, a principios del siglo XX, llegó a decir que "lo accidentado del suelo impide el cultivo de regadío, que en este valle [del Genal] puede decirse que no existe. Salvo en algún que otro pequeño recodo del río que permite la implantación de un huerto de naranjos y hortalizas regado por acequias, el resto del valle es de secano". Esta expresión sólo puede explicarse por un conocimiento 'distante' del Valle -desde lo alto de sierra Bermeja, podríamos decir-. 


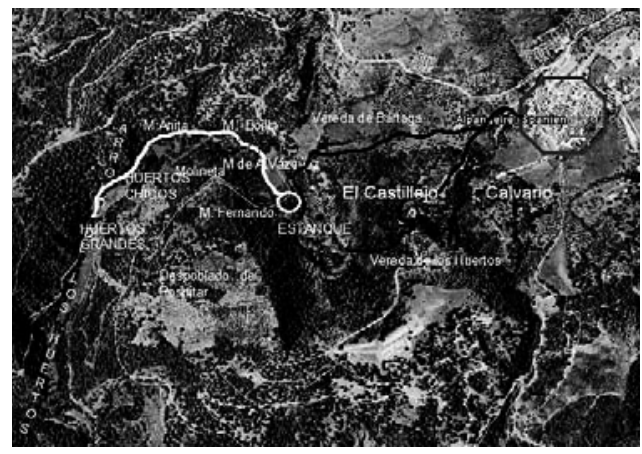

10. Esquema Alpandeire sobre imagen Google 2004

La significación histórica y cultural de estos sistemas de cultivo intensivo en el Genal es tal que su existencia va aparejada al establecimiento de una red de hábitat permanentes como hasta entonces no se había dado. No sabemos de cuándo datan exactamente las huertas; les suponemos origen medieval y paralelo a los núcleos de población, aunque en los siglos posteriores -en el XVIII, especialmente en el XIX, y también en el XX- algunas han podido ser ampliadas y otras han desaparecido.

En época subactual, estas huertas -en régimen de propiedad o en arrendamiento- tenían orientación comercial, aunque las dificultades de transporte en el Valle -hasta hace unas décadas tenía que ser a lomos de bestia- encarecían la producción dificultando su salida al mercado. Se cultivaban principalmente frutales (en general, y especialmente cerezos y naranjos) y hortalizas; y no hace mucho tiempo también tabaco. Hoy, muchas de ellas están abandonadas.

Los sistemas hidráulicos que hoy vemos, en activo o fósiles, son -por lo generallocales, aunque en algunos casos afectan a municipios colindantes, y han supuesto uno de los principales elementos de interacción social a escala local y supralocal.

Casi al azar, vamos a detenernos brevemente en los Huertos de Alpandeire [10].

Alpandeire es una pequeña población 42 . Cabrillana refiere que las "ricas tierras de vega" de Alpandeire mantenían a cincuenta y una familias en época morisca. Los Huertos es el área de cultivo de regadío más grande y próxima a Alpandeire, y más cercana aún al despoblado morisco de Pospitar. Se extiende desde El Foncal hasta La Junta con el arroyo de Gorgote. Se riega con el agua del Nacimiento de los Bancales y del Nacimientillo, acumulándola previamente en el Estanque, una alberca colectiva de forma circular de la que arranca la acequia de los Huertos. Esta acequia, antes terriza, está ahora cementada como sus quebraderos -partidores-.

Los regantes mencionan un alcalde de aguas como figura arbitral, que no era elegido ni pagado, sino que así era designado el regante que estaba al final del sistema -correspondiendo con el cabero de las huertas de la Meseta rondeña-, de modo

42 Según el Instituto de Estadística de Andalucía, el municipio tenía 278 habitantes en el año 2008. 
que estaba especialmente interesado en el buen funcionamiento del sistema para que a su parcela también llegara el agua.

Cada usuario del sistema participaba, cuando así lo disponía el alcalde de aguas en la limpieza de la alberca, el Estanque, y de la acequia hasta el quebradero de su bancal. Las mujeres trabajaban en la huerta y regaban, pero no participaban en el mantenimiento -limpieza, especialmente- del sistema. No había albercas particulares.

En la temporada de riego, se dejaba llenar el Estanque durante la noche. " $A l$ apuntar el sol" se abría para empezar a regar. A las doce del día se volvía a tapar. A las cuatro de la tarde se volvía a abrir, y al ponerse el sol se tapaba hasta el día siguiente. De modo que sólo se regaba de día.

El agua se distribuía por turnos de horas y días en una tanda semanal entre las diferentes huertas: las de arriba, a las que correspondía "el bose" (lo que bosa o rebosa) de la alberca los domingos por la mañana; las huertas chicas, a las que les correspondían el lunes y el martes; y las grandes, las de abajo, que tenían todos los días de la semana.

El agua del Estanque "íba toda junta hasta el Molino de Anita. Allí partía, y una iba llana hasta la Molinilla -algunos dicen Molineta- $y$ otra la dejaban caer al arroyo", que se aprovechaba "para echar el agua abajo", hacia los otros huertos y molinos. En la Molinilla volvía a partirse, "una para los huertos chicos y otra que volvía al arroyo", para los huertos y los molinos de abajo.

Las protoindustrias localizadas a lo largo del tiempo en esos sistemas hidráulicos del valle son molinos harineros, de aceite y de zumaque, además de alguna sierra hidráulica, tenerías, una ferrería, y otras industrias sin determinar.

En los usos actuales del agua, todos -salvo excepción- se han convertido en consuntivos de manera que no se reutiliza el agua. Esa excepción la constituyen las fuentes públicas, aunque en algunos casos la apropiación de que han sido objeto ha pervertido el uso de origen. El carácter finalista de los usos supone también una simplificación de la interactividad de los agentes sociales relacionados. La fragilidad de los sistemas hidráulicos y su desintegración en las últimas décadas se evidencia también en la debilidad de la estructura asociativa de los usuarios. La mayor parte de las agrupaciones de regantes no tienen -salvo en Igualeja- reconocidos sus aprovechamientos históricos y siguen tomando y repartiendo el agua en una especie de uso consuetudinario modificado y adaptado a la marginalidad creciente de la actividad.

En 1985, en el Plan especial de protección del Medio Físico de la provincia de Málaga y Catálogo de espacios y bienes protegidos (PEPMF), se preveía la redacción de Normas subsidiarias de ámbito supramunicipal en el Valle del Genal, atendiendo a la necesidad de contar estos municipios (Parauta, Cartajima, Igualeja, Júzcar, Pujerra, Faraján, Alpandeire, Atajate, Benadalid, Benalauría, Algatocín, Jubrique, Benarrabá y Genalguacil) con algo más que una "Delimitación de Suelo Urbano", y al hecho de ser considerados "núcleos de población integrados en el paisaje". No se llegaron a hacer.

En 1993, las corporaciones municipales de Benadalid y Benalauría, movidas por el interés de proteger el patrimonio arquitectónico y urbanístico de sus respecti- 
vos núcleos de población ante la creciente demanda de renovación -perfectamente explicable- y de nueva construcción, y la amenaza que representaba la consiguiente aplicación de la ordenanza de edificación de la normativa urbanística provincial entonces vigente, solicitaron para sus respectivos núcleos de población la incoación de expediente de declaración BIC como Lugar de Interés Etnológico43. La Comisión Provincial de Patrimonio propuso a la Consejería la incoación de esos expedientes. La visita de los responsables y técnicos de la Dirección General de Bienes Culturales concluyó que dado que el problema era común a los otros pueblos del valle del Genal, la solución también debería serlo, de modo que lo adecuado sería un plan para todos, que pronto -se decía- se emprendería. Aquel planteamiento, en principio correcto, fue aceptado por ambos Ayuntamientos. Pero pasado el tiempo sin que hubiera nada, el "ir todos juntos", significó una forma de castigo para los que querían "ir más deprisa" cuando otros -incluida la instancia administrativa competente- ni siquiera se habían "puesto en pie". Y el deterioro llegó, imparable. La arquitectura vernácula empieza a ser un bien escaso en el valle del Genal. Tanto dentro de los cascos urbanos como en el campo van desapareciendo, abandonadas, las construcciones vernáculas y los espacios a ellas vinculados, sustituidas por nuevos tipos de vivienda, en algunos casos de mejor habitabilidad, pero sin duda estandarizados a partir de un denominado "estilo turismo rural".

En 2006, veintiún años después del PEPMF, fueron presentados los documentos de avance del Plan General de Ordenación Urbanística (PGOU) de once de ellos (Algatocín, Alpandeire, Benadalid, Benalauría, Benarrabá, Faraján, Genalguacil, Igualeja, Jubrique, Júzcar, Pujerra) redactados por la Diputación de Málaga44.

Afortunadamente, esos PGOU están aún en fase de redacción, porque, dado que el objetivo de los mismos es regular los usos urbanos, esto es, dibujar los "desarrollos urbanísticos" de las nuevas áreas de construcción que se prevén tanto en los núcleos como en el diseminado, el patrimonio cultural no sale muy bien parado, podríamos decir. De hecho, el uso rural es determinado como "incompatible" 45 .

El concepto de paisaje que en allí se maneja es puramente superficial: "es la manifestación externa del territorio y está íntimamente relacionada con la percepción del sujeto o lo que el observador es capaz de percibir. El paisaje es el espacio que rodea al observador o el entorno visual del punto de observación"46. Además, como se dice que "la belleza de este paisaje es el valor principal de su deterioro", los desmanes parecen estar justificados.

Los Catálogos de Patrimonio adjuntos a estos planes presentan un repertorio

\footnotetext{
43 En base a dos informes elaborados por quien esto escribe.

44 Se pueden consultar en la página web de la Diputación Provincial.

45 En las Ordenanzas particulares para el núcleo tradicional establecidas en la Normativa urbanística se dice que el uso dominante es el residencial (Art.14.1), mientras los usos incompatibles (Art.14.3) son el rural, la gran superficie comercial, el funerario, el uso de la pequeña, mediana y gran industria así como la industria agropecuaria.

46 Avance del PGOU de Algatocín 2006, pág. 104.
} 
-escaso- de elementos -edificios- singulares y aislados, y muestran un conocimiento del 'terreno' que, excepto en lo arqueológico -realmente exhaustivo ${ }^{47}$-, no parece ir más allá del "viaje exploratorio". Igualmente carecen de exposición de criterios que justifiquen la inclusión o no de un inmueble en el mismo, ni para determinar el grado de protección que se le adjudica.

En ese sentido, resulta especialmente incongruente la distinción entre tres categorías de patrimonio: histórico, arqueológico y etnográfico. En primer lugar, porque el denominado patrimonio etnográfico es puramente nominal, reducido a la vivienda y a alguna fuente en el núcleo, a algunos molinos y lagares, algunas cruces, hornos y otros elementos aislados en el diseminado, que son contemplados como meros inmuebles de interés "ambiental", como si fuera resultado de la 'mirada' formalista tan habitual en el arqueólogo o en el historiador del arte. Y en segundo lugar, porque esa clasificación, y desde esa 'mirada', conlleva la inconveniente determinación apriorística del grado de protección para cada tipo de bien patrimonial. O es relevante el bien, y hay que conservarlo y protegerlo, o no es relevante y no hay que intervenir; pero no es más relevante un bien porque sea susceptible de ser estudiado con metodología arqueológica o porque lo sea con metodología antropológica, o histórica, o por todas ellas juntas.

En cualquier caso, en pleno cumplimiento de la ley 48 , no se establece más protección efectiva de la que afecta a lo arqueológico y a los monumentos, que en este caso se reducen a las iglesias. Se citan otros inmuebles más, individualizados, descontextualizados, pero sin protección alguna.

Sobre la arquitectura tradicional, ese conjunto de elementos que nunca se pretendieron singulares y que reúne valores históricos, artísticos y culturales, en muy pocos casos son tenidos en cuenta otras cualidades que las referidos a la imagen exterior de los edificios, ni más criterio que el "fachadista", formalista y decorativista. La atención que en comparación se presta a cuestiones relativamente banales como los detalles ornamentales parece reveladora de que su presencia o no, ha podido determinar impropiamente la inclusión del inmueble en el catálogo. En cualquier caso, resulta un error tratar de establecer una reserva formada por una serie limitada de elementos históricos o tradicionales que en un plazo mayor o menor de tiempo se convertirán en "islas" artificiales y descontextualizadas en un entorno radicalmente transformado, donde acabarán siendo percibidas como elementos obsoletos, no en sí mismos sino por contraste con su entorno transformado. Precisamente, en la mayor parte de los casos no ocurre así en la actualidad, pues comparten con su contexto urbano unas características comunes que son precisamente las que hay que proteger, porque sólo mediante la salvaguarda del medio se puede garantizar la pervivencia, el buen funcionamiento y la lógica de los elementos que lo integran: no

\footnotetext{
47 Más teniendo en cuenta que la Diputación Provincial cuenta para lo relacionado con el Patrimonio en toda la provincia con un solo técnico.

48 Para el planeamiento, la Ley 14/2007 de Patrimonio Histórico de Andalucía no obliga a más análisis que el arqueológico [Art. 29.1], al que se añade lo que ya esté "identificado" por la Administración competente.
} 
se trata de atesorar -descontextualizadas- unas cuantas frases -o palabras- más o menos geniales, sino de permitir que el relato que compone la arquitectura heredada siga estando articulado, mantenga la significación que lo hace valioso y comprensible, y siga ofreciendo así los beneficios que desde el punto de vista cultural, funcional y visual ha venido ofreciendo.

También se ignora la categoría de bienes culturales que tienen las vegas y huertas del Valle del Genal y el carácter monumental que en conjunto tienen estos complejos sistemas de captación y conducción de agua, los espacios irrigados y las estructuras de transformación; se omite su valor social, se desdeña su valor ambiental; se renuncia al mantenimiento de un paisaje cultural reduciéndolo a la marginalidad, sin haber intentado -ni siquiera estudiado- la viabilidad de espacios de tanto valor social y cultural como éstos.

Es curioso cómo en Alpandeire se mencionan como inmuebles a proteger una serie de molinos en ruinas a lo largo de la acequia de los Huertos, pero son "olvidados" el Estanque y las huertas, los elementos que aquilatan y articulan el valor social principal. Y que, como los molinos, podrían, en último caso, ser clasificados como "arqueológicos".

Se olvida que el principal activo del valle del Genal es su cultura en el sentido más amplio del término, que se manifiesta en un paisaje en mosaico resultado de su propia historia -incluyendo lo que absurdamente se clasifica como Medio Ambiente, imposible de comprender separado de la cultura-. Son los espacios agrícolas, ganaderos, forestales y de hábitat, en ese medio físico concreto, lo que caracteriza y singulariza el Genal. Pero como espacios vivos, activos productiva y socialmente.

Afortunadamente, la redacción de estos Planes y Catálogos es aún provisional.

\section{A MODO DE CONCLUSIÓN.}

Por traer a colación un caso -y salvando las distancias socioeconómicas-, podríamos hablar de la consideración de éstos valores en los sistemas de regadío tradicionales en el Valais suizo, donde las acequias son consideradas como "equipamiento" agrícola o turístico 49 , según los $\operatorname{casos}^{50}$, e incluidas en la normativa de planeamiento y, aplicando así los principios de ordenación del territorio ${ }^{51}$ dar respuesta a diferentes demandas: 1) salvaguarda de los sitios de valor y los elementos culturales, 2) refuerzo del turismo extensivo y "blando", y 3) respeto a la diversidad de los elementos estructurantes del paisaje.

Desde el punto de vista del patrimonio sociocultural -como señalan algunos investigadores suizos, y en especial Crettaz- no se llega a valorar estos elementos

49 REYNARD, E. (1995) “L'irrigation par les bisses en Valais. Approche géographique”. Les bisses. Actes du Colloque International. Annales Valaisannes, S.H.V.R. pág. 47.

50 REYNARD, E. (1995) op. cit.. pág. 58.

51 SCHWERY, R. (1995) "Inventaire, classement, politique de mise en oeuvre et mesures de protection des bisses en Valais". Les bisses. Actes du Colloque International. Annales Valaisannes, S.H.V.R. págs. 173-185. 
hasta que los cambios -las mutaciones- en la estructura productiva los convierten en excepcionales; se inicia así el proceso de selección de elementos "espectaculares" a "heroizar" y "emblematizar", "disneylandizar"52 en definitiva, privilegiando las "individualidades" con un "bricolaje de restos"53 sobre el "conjunto" -que pierde así la totalidad de su sentido social- en perfecta coherencia con la lógica moderna y posmoderna: lo moderno e innovador junto con lo arcaizante -inventado-, reforzándose uno a otro; como expresa Crettaz siguiendo a M. Foucault 54 , produciendo una doble arqueología del paisaje: aquella objeto de la arqueología propiamente dicha, y aquella otra del discurso y de lo visible ${ }^{55}$.

La cuestión principal radica en la necesidad de una visión integradora del Patrimonio, basada en soluciones globales y locales, afrontando la realidad de sus manifestaciones inmuebles, muebles y de actividad, en su propio contexto socioeconómico. Para cada caso es necesario partir del análisis histórico, social y económico de la comunidad afectada, de la relación entre hábitat y área de producción, de sus perspectivas de futuro, de las implicaciones de los cambios de forma de vida con la introducción y potenciación de nuevos recursos económicos, con el fin de determinar los instrumentos de tutela adecuados y su puesta en práctica. Hay que documentar lo existente, y a partir de ahí, estudiar el mantenimiento de los usos y el aprovechamiento posible. Hay que evitar que el paisaje que llevan aparejadas las figuras de protección se convierta en un mero escenario "pintoresco", y habrá que superar la concepción "arqueologista" -en el sentido más restrictivo del término- de los bienes culturales.

La protección de este tipo de patrimonio 'histórico-arqueológico-etnológico' debería ser un objetivo prioritario, al tener fuertes implicaciones en el desarrollo local y al tratarse de un patrimonio vivo, tan vulnerable, de recuperación imposible por la falsedad que ésta supondría. La orientación hacia el marco territorial debe superar el reduccionismo de la 'urbanización/ordenación de territorio' entendida como 'delineación' desde la 'racionalidad' del arquitecto-urbanista erigido en técnico único, con el complemento -absolutamente subordinado, en todo caso- del arqueólogo y del historiador del arte, y dar lugar a nuevas miradas y nuevos puntos de vista y, desde

\footnotetext{
52 CRETTAZ, B. (1995) "Autour du bisse. Pour une problématique globale". Les bisses. Actes du Colloque International. Annales Valaisannes, S.H.V.R., pág. 18. Y añado yo: obviando, claro, la creatividad, la calidad y la excelencia que caracterizan a los productos Disney.

53 Ibídem., pág. 22.

54 Ibídem., pág. 26.

55 CRETTAZ, B. Ibídem., pág. 31 de modo más crudo y concluyente: "Estamos actualmente en esta fase nueva de posmodernidad, una de cuyas características, para los Alpes, es la movilización exhaustiva de todos los restos de cara a neobricolajes publicitarios, mediáticos, arquitectónicos, u otros. [...] Preparados, así como he dicho más arriba, por un largo proceso de emblematización, la acequia-resto está preparada para una etapa nueva en el Disneyland alpino. Se podría incluso afirmar que la acequia puede estar asegurada más que ningún otro resto, de un incremento de interés y de moda, al satisfacer a todos los actores de la disneylandización: los indígenas [...], los indígenas ambientalistas [...], los ecologistas [...], los promotores turísticos y los responsables de márquetin [...], el turista en general [...], el investigador [...], ignorando a veces que participa en la puesta en valor científico-mediático-ecológico-turístico de la "vieja acequia" convertida en último resto". Traducción propia.
} 
luego, a la participación de los directamente interesados.

Los inmuebles pueden, y deben, estar protegidos desde la normativa urbanística, teniendo en cuenta la diversidad de su naturaleza: desde infraestructuras de producción y transformación que constituyen un solo inmueble, hasta de amplio desarrollo geográfico, como los sistemas hidráulicos, las redes viarias tradicionales-, o la vivienda; así como los lugares con o sin estructuras arquitectónicas asociadas, tanto en hábitat concentrado como en disperso; unos pueden ser tratados, a priori, desde la singularidad, porque así han sido concebidos e interpretados: como expresión de un estatus social, o como manifestación de una funcionalidad concreta; pero otros, y especialmente las estructuras productivas, sólo cobran sentido en el conjunto.

Inseparables del "paisaje", las actividades productivas "tradicionales" también tener el reconocimiento de su valor cultural que permita su viabilidad, orientándolos a la producción de calidad que rentabilice la actividad y capitalice la plusvalía de siglos de creación y mantenimiento. Tal vez para algunos esto pudiera parecer un tanto 'artificial', por lo que supone de intervención al margen de la 'selección natural de 'los tiempos' o 'del mercado'; pero si en beneficio del Patrimonio Cultural se admite la protección y conservación de los inmuebles -y del paisaje considerado inmueble-, no parece haber razón para no dar tratamiento igual a la actividad que los crea y mantiene, entendida en este caso como protección conservativa. Proteger no es solamente limitar y controlar, es también asesorar y prevenir.

En último caso, el mantenimiento de las actividades "tradicionales" implica el reconocimiento del derecho a la libertad de promoción, de elección, de identificación.

La pérdida de espacios y lugares es exponente de un cambio drástico en la concepción del paisaje, que ha pasado de ser espacio cultural interactivo a ser escenario de uso turístico, sin reparar en que la actividad primaria que lo produce es la misma que asegura su pervivencia. No se trata sólo de una mera cuestión estética, sino puramente cultural: la terciarización de una economía poco antes primaria no puede dejar de tener efectos en la naturaleza de la comunidad 56 y en todo lo que de ella resulta. Los cambios son inevitables, y en tantos casos deseables. El modo en que estos se producen y los resultados que dan no siempre significan una mejora.

El seguidismo de las categorías administrativas de tutela del Patrimonio cultural parece dirigido a reservar parcelas sectoriales de actividad, cuando no a respaldar estrategias contrarias a una visión integrada del Patrimonio. Los prejuicios y los clichés derivados de la idea de "tesoro" -especialmente 'artístico-arqueológico', la lentitud cuando no la inacción de la Administración competente, el excesivo peso de 'lo urbanístico' -con el 'hipertrofiado' el papel del arquitecto/urbanista-, al que se ha unido en los últimos tiempos el lastre de "lo turístico" -y el advenimiento de los gestores turístico-culturales-, imposibilitan una gestión efectiva del Patrimonio. En definitiva, la gestión del Patrimonio es una tarea compleja, que no complicada, no tanto

56 SANTANA, A. (1997) Antropología y turismo. ¿Nuevas hordas, viejas culturas? pág. 79. 
por cuestiones técnicas sino, especialmente, por la cantidad de intereses que se entremezclan, principalmente económicos (inmobiliarios) y políticos (en el sentido más partidista del término). El escaso dinero del que (salvo 'proyectos emblemáticos', esto es, susceptibles de rápida rentabilidad política) se suele disponer, junto con la práctica ausencia de sector privado y de participación ciudadana, son las muestras más notables de una realidad que bascula encorsetada entre la precariedad y la virtualidad.

El resultado de aplicar un modelo parcial y discutible, como hasta ahora, que sólo tiene en perspectiva el presente (de algunos ${ }^{57}$ ) más inmediato, puede tener como consecuencia la hipoteca del futuro. Frigiliana funcionó durante algún tiempo como modelo para los núcleos del Genal. Hoy es más bien un 'aviso' de lo que se avecina. Por eso, precisamente, podría (¿aún?) ser éste último el sitio de ensayo de otra manera de entender la gestión del patrimonio cultural en el medio rural, su significado y su posible aprovechamiento/disfrute, para redefinir los términos de una dialéctica tan desigual.

A fin de cuentas, como dice Martínez de Pisón, "el único documento de la Historia que no está archivado es el paisaje y es de todos, incluso de los que aún están por nacer"58.

57 HERGET, W. , GUERRERO, J. y COMPÁN, D. (1996) "La acequia de Aynadamar y su entorno. El sacrificio de un patrimonio en aras de intereses sectoriales”. Paderborn Geographische Schriften, 10.

58 "Entrevista a Eduardo Martínez de Pisón, Catedrático de la UAM" por Maribel del Álamo. Revista Ambienta, noviembre 2002:17. 
